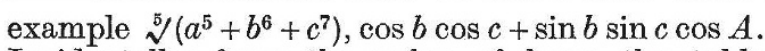
Incidentally from the value of $\log n$ the table gives without interpolation $\log (n+1), \log (n-1)$, $\log \frac{n+1}{n}, \log \frac{n-1}{n}$, and the logarithms of the reciprocals. This is a most useful table for five figure calculations with logarithms.

\section{M. Milne-Thomson.}

Advanced Trigonometry. By C. V. Durell and A. Robson. Pp. viii +335 . (London: G. Bell and Sons, Ltd., 1930.) $8 s .6 d$.

THIs volume, dealing mainly with analytical trigonometry, provides an excellent school course for senior scholars. It embraces the logarithmic, exponential, and hyperbolic functions ; expansion in power series; projection and finite series, and complex numbers. No hesitation has been shown in using the methods of the calculus throughout, and a commendable feature is the development and application of the powerful principle of inequalities. The section devoted to complex numbers, occupying considerably more than half the book, is especially noteworthy for its clearness and sound treatment. As the authors point out, the interest and value of higher trigonometry lies in its being an introduction to modern analysis and, for this reason, the methods by which results are obtained are of more importance educationally than the results themselves. This is the basic principle upon which the book has been written.

The extreme rigour which characterises modern analysis is, as every teacher knows, quite out of place in a school course, with the consequence that many of the standard treatises are unsuitable for teaching purposes outside the universities. The present volume therefore, written by experienced teachers who fully appreciate the difficulties in the work of mathematical instruction, can be thoroughly recommended as a fresh and inspiring survey of a difficult section of school mathematics.

Rationalization. By Dr. James A. Bowie. Pp. 36.

(London: Sir Isaac Pitman and Sons, Ltd., 1931.) 1s. net.

ONE of the best signs for the future of British industries is the interest now being taken in problems of industrial reorganisation. In this connexion, 'rationalisation' has frequently been proposed as a remedy for industrial ills, but the meaning of the term is vague and may serve indeed rather to obscure than to clarify discussion of these problems. Dr. Bowie has performed, therefore, a real service in providing a critical examination of its implications and methods in this pamphlet. Defining rationalisation as the conscious control and readjustment of industry, he points out that it has two sides: one external, concerned with the grouping of a large number of previously independent, competing enterprises, and the other internal, concerned with the efficient organisation within each unit of the functions of production, finance, personnel, and distribution. In examining the various implications of his subject, Dr. Bowie discusses such questions as vertical versus horizontal combinations, the mechanics of rationalisation, the planning of production, the problem of labour, the problem of control, and labour co-operation.

Constitution et thermochimie des molécules: les constituants moléculaires, les liaisons intramoléculaires, la valeur énergétique des liaisons. Par Albert Gosselin et Marcel Gosselin. Pp. vii +231. (Paris: Les Presses universitaires de France, 1930.)

THIs volume contains a brief account of the three types of valency which are now generally recognised as definitely distinct in character. The descriptive portion is followed by thermochemical data on the heats of formation of compounds from which the thermal values for the energy required to rupture different bonds in complex molecules are calculated. These in turn are employed to elucidate the structure of numerous compounds. Some of the formulæ proposed, for example, $\mathrm{H}_{2}-\mathrm{C}{ }_{. \mathrm{H}}^{. \mathrm{H}}$ for methane, $\mathrm{H}_{2}-\mathrm{N}$ - . $\mathrm{H}$ for ammonia, and NH-CO-NH for urea, are so different from those usually accepted, and the evidence advanced in favour of them is so problematical in character, that the book must be regarded as one which might be somewhat unsafe as a text-book. It does, nevertheless, contain many interesting observations on reactivity of organic compounds.

E. K. R.

Synthetic Inorganic Chemistry : a Course of Laboratory and Classroom Study for First Year College Students. By Prof. Arthur A. Blanchard and Prof. Joseph W. Phelan. Fourth edition. Pp. xii + 352. (New York: John Wiley and Sons, Inc. ; London : Chapman and Hall, Ltd., 1930.) 15s. net.

THIs book contains a course of experiments and preparations in inorganic chemistry covering all the groups in the periodic system. Full details of the experimental procedure are given. The elementary theory of ionisation and that of mass action are included, and numerous questions and problems are given both in the text and at the ends of the chapters. The book is similar in plan to Biltz' "Laboratory Methods of Inorganic Chemistry", but is more elementary, and it provides a clear and useful course of experimental work in preparative inorganic chemistry, which could supplement the instruction in analysis usually given to degree students. Many of the preparations are suitable for pupils in the higher forms in schools.

Some Modern Mediums. By Theodore Besterman. Pp. xi $+189+4$ plates. (London: Methuen and Co., Ltd., 1930.) 7s. $6 d$. net.

IN this book, the author has made a genuine attempt to present his case in a more or less unbiased manner. He is quite honest in his admission that several well-known mediums have turned out to be frauds. Mrs. Piper be considers perfectly genuine. So much evidence with regard to mediumistic performances consists of a "has not been found out' attitude, that it is interesting to read evidence of a positive nature. 